\title{
Extracytoplasmic diaphorase activity of Streptomyces coelicolor A3(2)
}

Ken-Ichi Oinuma, Itaru Yamaguchi, Daiki Shindo, Masahiro Fujimoto, Tatsuya Nishiyama, Hideaki Takano, Naoki Takaya, Kenji Ueda

\begin{tabular}{|c|c|}
\hline Citation & Biochemical and Biophysical Research Communications. 503(3); 1581-1586 \\
\hline Issue Date & 2018-09-10 \\
\hline Type & Journal article \\
\hline Textversion & Author \\
\hline Highlights & $\begin{array}{l}\cdot \text { Streptomyces coelicolor produces extracytoplasmic diaphorase. } \\
\cdot \text { The enzyme has been identified as SCO2180 gene product. } \\
\cdot \text { SCO2180 catalyzes reduction of various quinonic compounds. } \\
\text {-The enzyme may play important role in the saprophytic life of Streptomyces. }\end{array}$ \\
\hline Rights & $\begin{array}{l}\text { (C) } 2018 \text { Elsevier Inc. This manuscript version is made available under the } \\
\text { CC-BY-NC-ND } 4.0 \text { License. http://creativecommons.org/licenses/by-nc-nd/4.0/. } \\
\text { This is the accepted manuscript version. Please cite only the published version. The } \\
\text { article has been published in final form at https://doi.org/10.1016/j.bbrc.2018.07.083. }\end{array}$ \\
\hline DOI & 10.1016/j.bbrc.2018.07.083 \\
\hline
\end{tabular}

Self-Archiving by Author(s)

Placed on: Osaka City University

OINUMA, K.-I., YAMAGUCHI, I., SHINDO, D., FUJIMOTO, M., NISHIYAMA, T., TAKANO, H., TAKAYA, N., \& UEDA, K. (2018). Extracytoplasmic diaphorase activity of Streptomyces coelicolor A3(2). Biochemical and Biophysical Research Communications. 503, 1581-1586. doi: 
Extracytoplasmic diaphorase activity of Streptomyces coelicolor A3(2)

Running title: Diaphorase of Streptomyces

Ken-Ichi Oinuma ${ }^{\mathrm{a} 1 *}$, Itaru Yamaguchi ${ }^{\mathrm{a}}$, Daiki Shindo ${ }^{\mathrm{a}}$, Masahiro Fujimoto ${ }^{\mathrm{a}}$, Tatsuya Nishiyama ${ }^{a}$, Hideaki Takano $^{a}$, Naoki Takaya ${ }^{b}$ and Kenji Ueda ${ }^{a *}$

aLife Science Research Center, College of Bioresource Sciences, Nihon University 1866 Kameino, Fujisawa, Kanagawa 252-0880, Japan

${ }^{\mathrm{b}}$ Faculty of Life and Environmental Sciences, University of Tsukuba

1-1-1 Tennodai, Tsukuba, Ibaraki 305-8572, Japan

Present address:

${ }^{1}$ Department of Bacteriology, Osaka City University Graduate School of Medicine, 1-4-3 Asahimachi, Abeno-ku, Osaka 545-8585, Japan

${ }^{*}$ Corresponding authors

E-mail addresses:

oinuma.kenichi@med.osaka-cu.ac.jp (K. Oinuma)

ueda.kenji@nihon-u.ac.jp (K. Ueda) 


\begin{abstract}
Metabolism of quinolic substances is fundamental to the saprophytic growth of Streptomyces. Here, we studied an enzyme activity reducing 2,6-dichlorophenolindophenol and nitroblue tetrazolium in the culture supernatant of Streptomyces coelicolor A3(2). N-terminal amino acid sequencing of a nitroblue tetrazolium-reducing enzyme revealed that the enzyme corresponds to the SCO2180 product. The protein exhibited a marked similarity with dihydrolipoamide dehydrogenase, the E3 subunit of 2-oxo-acid dehydrogenase complex. A recombinant SCO2180 protein formed a homodimer and exhibited a diaphorase activity catalyzing NADH-dependent reduction of various quinolic substrates. Similar nitroblue tetrazolium-reducing activities were observed for other Streptomyces strains isolated from soil, implying that the diaphorase-catalyzed reduction of quinolic substances widely occurs in the extracytoplasmic space of Streptomyces.
\end{abstract}

\title{
Keywords
}

Streptomyces coelicolor, extracytoplasmic diaphorase; dihydrolipoamide dehydrogenase

\section{Introduction}

Actinomycetes is a group of gram-positive aerobic bacteria that are most commonly found in soil $[1,2]$. Some typical actinomycetes including Streptomyces species are featured by their morphology that involves growth in filamentous forms and 
the following differentiation that eventually leads to spore formation. Actinomycetes are also well-known in their ability to produce various secondary metabolites such as antibiotics. This has made this group of organisms important in terms of industrial use. Enormous efforts have been made to elucidate the molecular mechanism that controls morphological differentiation and secondary metabolism in some model Streptomyces strains including Streptomyces coelicolor A3(2), the best-studied model organism.

We are interested in the physiology of Streptomyces fundamental to its growth in the natural environment. Soil contains humic substances consisting of phenolic macromolecules derived from dead plant materials. The use of a solid medium containing humic acid (HV agar) facilitates selective isolation of Streptomyces and related bacteria [3]. This infers that these bacteria have an ability to metabolize the plant-derived macro-compounds. Actually, we discovered that Streptomyces griseus excretes a laccase-like phenol oxidase EpoA [4, 5]. Currently, this kind of Streptomyces enzyme is called SLAC (small laccase), and extensively studied for its application to biomass degradation technology $[6,7]$.

Dihydrolipoamide dehydrogenase (DLDH) is an integral component of 2-oxoacid dehydrogenase including pyruvate dehydrogenase and 2-oxoglutarate dehydrogenase [8]. Pyruvate dehydrogenase is a huge molecule composed of multiple decarboxylases (E1), dihydrolipoamide transacetylases (E2), and DLDHs (E3). The 2-oxoglutarate dehydrogenase complex has a similar architecture. In the reaction cycle of these enzymes, DLDH catalyzes oxidation of dihydrolipoamide to lipoamide in a FAD- and $\mathrm{NAD}^{+}$-dependent manner. In addition to the well-characterized physiological role as a component of 2-oxiacid dehydrogenase, some DLDHs are known to show a dye-reducing activity using $\mathrm{NADH}$ as an electron donor. Flavin-bound enzymes that 
exert such pyridine nucleotide-dependent reduction of dyes are called diaphorases [9].

In this work, we discovered a dye-reducing enzyme in the culture supernatant of $S$. coelicolor A3(2). The purified enzyme was identified as the SCO2180 gene product exhibiting a marked similarity with DLDHs. The evidence suggests that this kind of enzyme catalyzes the reduction of quinolic substances in the extracytoplasmic space of S. coelicolor.

\section{Materials and Methods}

\section{Bacterial strains, plasmids, and growth conditions}

The parental strain S. coelicolor A3(2) M145 (designated as wild type, WT) and the cosmid clone library was obtained from the John Innes Centre, UK. S. griseus IFO13350 was obtained from the Institute for Fermentation, Osaka, Japan. Escherichia coli strain $\mathrm{DH} 5 \alpha$ (Takara Shuzo, Kyoto, Japan) was used as a host for conventional DNA manipulation. E. coli strains GM2163 and BW25141/pKD78 used for producing methylation-free DNA and disruption cosmids, respectively, were obtained from the Coli Genetic Stock Center at Yale University. E. coli Rosetta 2 (DE3) and pET-26b(+) plasmid (Novagen) were used for recombinant protein production. pWHM3, an E. coli-Streptomyces shuttle plasmid [10] was used for protein expression in S. coelicolor A3(2).

Streptomyces strains were routinely cultured at $28^{\circ} \mathrm{C}$ with shaking at $180 \mathrm{rpm}$ in Bennett's/sugar liquid medium $\left(1 \mathrm{~g} \mathrm{~L}^{-1}\right.$ yeast extract [Difco Laboratories, Detroit, Michigan], $1 \mathrm{~g} \mathrm{~L}^{-1}$ meat extract [Kyokuto, Tokyo, Japan], $2 \mathrm{~g} \mathrm{~L}^{-1} \mathrm{NZ}$ amine [Wako Pure Chemical Industries Ltd., Osaka, Japan], and $10 \mathrm{~g} \mathrm{~L}^{-1}$ of the appropriate sugar [pH 7.2]). 
R2YE medium was used for transformation [10]. E. coli strains were cultured in Luria-Bertani (LB) medium. E. coli transformants were selected with $50 \mu \mathrm{g} \mathrm{mL}^{-1}$ ampicillin (Wako), $40 \mu \mathrm{g} \mathrm{mL}^{-1}$ kanamycin, or $20 \mu \mathrm{g} \mathrm{mL}^{-1}$ apramycin. Streptomyces transformants were selected with $20 \mu \mathrm{g} \mathrm{mL}^{-1}$ of kanamycin, thiostreptone, or apramycin.

\section{Enzyme assay}

For purification study, 2,6-dichlorophenolindophenol (DCIP) and nitroblue tetrazolium (NBT) (Supplemental Fig. S1) were used as substrates. The DCIP-reducing activity was measured either semi-quantitatively with a 96-well clear flat bottom plate or quantitatively in a semimicrovolume disposable polystyrene cuvette placed in a spectrophotometer. The standard assay mixture for the quantitative method comprised $25 \mathrm{mM}$ sodium phosphate buffer ( $\mathrm{pH} 7.0), 0.2 \mathrm{mM} \mathrm{NADH}$, and $0.1 \mathrm{mM}$ DCIP in a total volume of $600 \mu \mathrm{l}$. The reaction was started by the addition of an appropriate amount of enzyme and carried out at room temperature. The activity was calculated from the rate of absorbance change at $600 \mathrm{~nm}$. The semi-quantitative method was performed in a similar way with the following differences. The reaction mixture comprised $45 \mathrm{mM}$ sodium phosphate buffer ( $\mathrm{pH} 7.0), 0.4 \mathrm{mM} \mathrm{NADH}$, and $0.1 \mathrm{mM}$ DCIP in a total volume of $200 \mu \mathrm{l}$. The activity was visually evaluated from fading of the blue color.

Blue-native PAGE [11] was performed with a native $10 \%$ polyacrylamide slab gel layered with a $4.5 \%$ stacking gel (36.5:1 acrylamide to bisacrylamide ratio). Tris-glycine buffer with and without the addition of NativePAGE Cathode Buffer Additive (20x) (Thermo Fisher Scientific, Waltham, MA) were used as the cathode and anode buffers, respectively. Novex Tris-Glycine Native Sample Buffer $(2 \times)$ (Thermo Fisher Scientific) was used as a loading dye. After proteins were separated at 150 volts for $4 \mathrm{~h}$ at room temperature, the gel 
was soaked in a staining solution consisting of $50 \mathrm{mM}$ potassium phosphate buffer $(\mathrm{pH} 8.0)$, $0.05 \mathrm{mg} \mathrm{mL}^{-1} \mathrm{NADH}$, and $0.1 \mathrm{mg} \mathrm{mL}^{-1} \mathrm{NBT}$ with gentle agitation until positive bands appeared. The following Coomassie brilliant blue R-250-staining visualized total protein.

\section{Purification of extracytoplasmic diaphorase from S. coelicolor A3(2) culture}

S. coelicolor A3(2) culture fluid was prepared from a 4-day culture of the WT strain in Bennett's/maltose medium. Cells were removed by centrifugation and filtration through filter paper. In the following purification steps, blue-native PAGE coupled with active staining with NBT as a coloring substrate was used to identify diaphorase-containing fractions. All column chromatographies were performed at room temperature. Sodium phosphate buffer $(50 \mathrm{mM}, \mathrm{pH} 7.0)$ was used throughout the purification. Proteins in the cleared culture medium (2 liters) were first fractionated by ammonium sulfate precipitation (35-70\% saturation) and then applied to a series of three connected HiTrap Q 5-mL columns (GE Healthcare, Chicago, IL). The bound proteins were eluted in a $300-\mathrm{mL}$ linear 0 to 0.5 $\mathrm{M} \mathrm{NaCl}$ gradient. The active fractions were pooled, and solid ammonium sulfate was added to give $30 \%$ saturation. Material was applied to a HiTrap Butyl HP 5-mL column (GE Healthcare) equilibrated with $30 \%$ ammonium sulfate-saturated buffer. The bound proteins were eluted by gradually lowering the concentration of ammonium sulfate from 30 to $0 \%$ saturation in $100 \mathrm{~mL}$ of buffer. The active fractions were combined, concentrated with an Amicon device (3,000 NMWL; Millipore, Burlington, MA), and loaded on a Superdex 200 10/300 GL column (GE Healthcare). Protein was eluted in distilled water without salt added. Diaphorase-containing fractions were collected and applied to a Mono Q 5/50 GL column (GE Healthcare). The bound protein was eluted from the column in a $20-\mathrm{mL}$ linear 0 to $1 \mathrm{M} \mathrm{NaCl}$ gradient. The active fractions were pooled and stored at $4^{\circ} \mathrm{C}$. 


\section{Gene disruption}

Gene disruption in S. coelicolor A3(2) was performed by using a homologous recombination technique based on Redirect technology [12]. The apramycin-resistance gene cassette construct used for each disruption were prepared by PCR using oligonucleotide primers GCCCGGCAGGACAGGGCCCACCCAAGGGCCGAGAACAATGATTCCGGGGATCC GTCGACC-3' and 5'-GCGGAAGTCTGTGTCGTCGCGCCCGAAGACCGAAGCGGTCATGTAGGCTGGA GCTGCTTC-3' (sequences corresponding to the apramycin resistance gene are underlined). The gene cassette was then substituted for the SCO2180 coding sequence on the corresponding cosmid clone by in vivo recombination by using $\lambda$ RED. The resulting apramycin-resistant cosmid purified from E. coli GM2163 were introduced into the WT strain of $S$. coelicolor $A 3(2)$ by PEG-protoplast transformation. Apramycin-resistant recombinants were then screened and checked for recombination by PCR using appropriate primer sets.

\section{Expression and purification of recombinant SCO2180}

The SCO2180 coding sequence (starting from the 30th condon through the 486th codon) was amplified by PCR using S. coelicolor A3(2) genome as a template. The sense primer (5'-CATATGAGCACCGTTTTCGACCTAGTGATC-3') and the antisense primer (5'-AAGCTTGTCGTGCATGTGGAGCGGCTTGCC-3') contained an additional restriction site (underlined) at the 5' end. The amplified DNA was first cloned into the pUC18 vector by TA cloning, and then subcloned into pET-26b(+) using the Ndel and HindllI restriction 
sites. E. coli Rosetta 2 (DE3) transformed with the resulting plasmid was used for expression of C-terminal His-tagged recombinant SCO2180 (rSCO2180). The recombinant cells were grown in LB medium containing kanamycin and chloramphenicol (50 $\mu \mathrm{gL}^{-1}$ ). When the optical density at $600 \mathrm{~nm}$ reached 0.3 , the culture was shifted to $28^{\circ} \mathrm{C}$ and rSCO2180 expression was induced with the addition of $0.4 \mathrm{mM}$ IPTG. After $4 \mathrm{~h}$ at $28^{\circ} \mathrm{C}$, the cells were harvested by centrifugation, suspended in $20 \mathrm{mM}$ sodium phosphate buffer ( $\mathrm{pH} 7.4)$, and lysed by sonication. $\mathrm{rSCO} 2180$ was purified from cell-free extract by HisTrap HP column (GE Healthcare) chromatography. Proteins were bound in buffer containing $140 \mathrm{mM} \mathrm{NaCl}$ and eluted in a linear 0 to $0.5 \mathrm{M}$ imidazole gradient. rSCO2180-containing fractions were pooled and stored at $4^{\circ} \mathrm{C}$.

The expression of an intact and N-terminally truncated SCO2180 in S. coelicolor A3(2) was performed as follows. The PCR amplification of the chimeric construct consisting of $h r d B$ promoter and the SCO2180 coding sequence was carried out using $\begin{array}{llll}\text { forward } & \text { for } & \text { frimer } & \text { promoter }\end{array}$ (5'-CTCGATGAATTCGCATAATTGTGGGGGGATGGCACC-3') (EcoRI restriction site is underlined), forward primer for SCO2180 coding sequence [5'-CCATCGTTCCGAGAGGTTGTTCATGAGCGGCCGGACACCAGCCGCC-3' (1M), 5'-CCATCGTTCCGAGAGGTTGTTCGTGGCGAACGACGCCAGCACCGTT-3' (25V), and 5'-CCATCGTTCCGAGAGGTTGTTCGTGAGCACCGTTTTCGACCTAGTGATC-3' (sequence serving as reverse primer for $h r d B$ promoter is underlined), and reverse primer for SCO2180 (5'-CTCGATGGATCCTCAGTCGTGCATGTGGAGCGGCTTGCC-3') (BamHI restriction site is underlined). The amplicon was digested with EcoRI and BamHI and inserted between the corresponding restriction sites of pWHM3 to generate pWHM3-1M, pWHM3-25V and pWHM3-30S. Thus prepared expression plasmids were introduced into 
the SCO2180 disruptant, and the resultant transformants were used for the protein localization study.

\section{Biochemical characterization}

The substrate specificity of SCO2180 was determined using purified rSCO2180. Test substrates were added to a standard assay mixture as electron acceptors in place of DCIP. Actinorhodin was prepared from S. coelicolor A3(2) cells as described previously [13]. NBT-reducing activity was evaluated from the rate of the absorbance change at 560 nm. Enzymatic activities for the other substrates were estimated from the consumption rate of $\mathrm{NADH}$ monitored at $340 \mathrm{~nm}$.

The molecular mass of the enzyme was determined using a Superdex 200 10/300 GL column. Sodium phosphate buffer (50 mM, pH 7.0) containing $0.15 \mathrm{M} \mathrm{NaCl}$ was used as the eluent. Gel Filtration Calibration Kits (LMW and HMW; GE Healthcare) were used for making a standard curve.

\section{Results}

DCIP-decolorizing activity in the culture supernatant of $S$. coelicolor A3(2)

A decolorization assay using DCIP as a substrate demonstrated that culture supernatant of $S$. coelicolor $\mathrm{A} 3(2)$ contained an NADH-dependent DCIP-reducing activity (Supplemental Fig. S1). The blue color of DCIP solution rapidly diminished after the addition of an ammonium sulfate-precipitated fraction of $S$. coelicolor $A 3(2)$ culture supernatant together with NADH. The activity was lost by boiling the fraction for $15 \mathrm{~min}$ (data not shown). These observations suggested that $S$. coelicolor A3(2) 
produces and secretes an NADH-dependent DCIP-reducing enzyme.

\section{Purification of the dye-reducing enzyme}

In order to identify the enzyme responsible for the $\mathrm{NADH}$-dependent dye-reduction, we tried to isolate it from the culture supernatant of $S$. coelicolor A3(2). However, the fractionation could not be effectively carried out due to the presence of multiple enzymes capable of reducing DCIP. Therefore, we switched the substrate to NBT, which was also reduced by the DCIP-reducing enzyme.

The use of NBT enabled us to detect the enzyme activity on a native polyacrylamide gel (blue-native PAGE). Time course analysis (Fig. 1) demonstrated that an NBT-reducing activity of ca. $100 \mathrm{kDa}$ is produced within cells in the early growth phase $(24 \mathrm{~h})$. Then, the enzyme of the same molecular size started to accumulate in the culture supernatant $(36 \mathrm{~h})$. Further, similar activities of different molecular sizes appeared in the culture supernatant in a later growth phase (48 h).

By following the activity on blue-native PAGE, the enzyme of ca. $100 \mathrm{kDa}$ was purified from the culture supernatant of $S$. coelicolor $A 3(2)$. The purified fraction contained a single band at ca. $50 \mathrm{kDa}$ on SDS polyacrylamide gel (Fig. 2). A subsequent Edman degradation analysis revealed that the $\mathrm{N}$-terminal amino acid sequence of the purified protein was: Ser-Thr-Val-Phe-Asp-Leu-Val-Ile-Leu-Gly-Gly-Gly-Ser-Gly-Gly-Tyr-Ala-Al-Ala-Leu. A database search revealed that this 20 -aa sequence fully matched with an $\mathrm{N}$-terminal region $\left({ }^{30}\right.$ Ser $-{ }^{49}$ Leu $)$ of the SCO2180 product consisting of 461 aa with a molecular mass of $51.3 \mathrm{kDa}$. This coincided with the mass of the purified protein observed in SDS-PAGE analysis. 
Table 1 summarizes the information regarding the coding sequences in the flanking region of SCO2180. SCO2180 protein exhibited a marked similarity with DLDH, the E3 component of 2-oxoacid dehydrogenase complex. SCO2180 located in the gene cluster consisting of 6 coding sequences encoding leucyl aminopeptidase (SCO2179), DLDH (SCO2180), 2-oxoacid dehydrogenase subunit E2 (SCO2181), a GntR family transcriptional regulator (SCO2182), 2-oxoacid dehydrogenase subunit E1 (SCO2183), and a transcriptional regulator (SCO2184). Gene cluster of the same organization was distributed to many other Streptomyces and related bacteria. The presence of the coding sequence for all the three components (E1-E3) in the same cluster indicated that the SCO2180 product serves as the E3 domain of a 2-oxoacid dehydrogenase complex.

\section{Biochemical characterization of SCO2180}

To biochemically characterize the SCO2180 product, a recombinant protein (rSCO2180) was expressed and purified from E. coli cells. The enzyme solution was yellow, and its UV-vis absorption spectrum indicated that the enzyme contained FAD as a cofactor (data not shown). A colorimetric enzyme assay confirmed that rSCO2180 catalyzes the reduction of DCIP (Supplemental Fig. S1) and NBT (data not shown) in an NADH-dependent manner. The enzyme also catalyzed reduction of several quinolic substrates (Table 2). Of these, the highest activity was observed for $p$-benzoquinone (3.67 $\mu \mathrm{mol} \mathrm{min}^{-1} \mathrm{mg}^{-1}$ ). Actinorhodin, the benzoisochromanequinone antibiotic produced by $S$. coelicolor A3(2), also served as a substrate.

Gel filtration analysis demonstrated that the apparent molecular mass of rSCO2180 was approximately $100 \mathrm{kDa}$ (Supplemental Fig. S2), indicating that the enzyme forms a 
homodimer. This was in agreement with the result of blue-native PAGE analysis (Fig. 2, right).

\section{Knockout mutant of SCO2180}

To obtain a clue to the physiological role of SCO2180, a knockout mutant of this gene was generated. The resultant mutant exhibited the same phenotype as the wild-type with respect to its growth efficiency, productivity of antibiotics and cell morphology (data not shown). This could be due to the activity of a paralogous enzyme compensating for the loss of SCO2180. Similar dispensability of DLDH is known for Ralstonia eutropha [14]. We also generated a recombinant S. coelicolor $A 3(2)$ strain harboring extra copies of SCO2180 on a high-copy-number plasmid, but the increase in the gene copy number neither affected the growth nor the phenotype of this strain (data not shown).

\section{Investigation of the localization of SCO2180}

The N-terminal amino acid sequence of the purified SCO2180 corresponded to ${ }^{30}$ Ser- ${ }^{49}$ Leu. We speculated that the $\mathrm{N}$-terminus region of pre-mature SCO2180 $\left({ }^{1}\right.$ Met- $\left.{ }^{29} \mathrm{Ala}\right)$ might function as a signal sequence that leads to secretion of the protein. To test this hypothesis, we constructed expression plasmids each containing an SCO2180 gene without/with a deletion at the N-terminus (Fig. 3A), and introduced them into the SCO2180 disruptant to let express SCO2180s from different start codons. We found that SCO2180 without a deletion was expressed most abundantly in the culture media among the SCO2180 derivatives tested (Fig. 3B). The deleted SCO2180s were all detected in the culture media although the amounts were less than half the level of 
undeleted SCO2180. The data suggest that the N-terminal signal-like sequence helps the protein be exported but is not necessary for the transportation process.

\section{Activity of soil isolates}

To assess the occurrence of intra- and extracytoplasmic diaphorase activity in other Streptomyces, cell-free extracts and spent culture media of randomly selected 18 Streptomyces soil isolates were subjected to blue-native PAGE. As shown in Fig. 4, the majority of the strains exhibited an NBT-reducing activity in not only their cell extract but culture supernatant, indicating that excretion of this kind of enzyme widely occurs in this group of soil bacteria. 


\section{Discussion}

In this study, we discovered that $S$. coelicolor $A 3(2)$ produces an $\mathrm{NADH}$-dependent dye-reducing enzyme in its culture supernatant. By pursuing the major activity that appears at ca. $100 \mathrm{kDa}$ in blue-native PAGE, the enzyme was successfully purified and identified as the SCO2180 product. An intriguing point of our discovery is that the SCO2180 product was isolated from the culture supernatant, indicating that the protein is translocated to extracytoplasmic space of S. coelicolor A3(2). This does not explain the role of the protein in keto-acid oxidation which should take place in the cytoplasmic space. The same phenomenon has been observed by Schrempf and coworkers in Streptomyces lividans, a close relative of S. coelicolor A3(2) [15]. The researchers discovered that not only proteins with secretion signals but those lacking the signature including an SCO2180 homolog are found outside the cells. Interestingly, those proteins are likely to be packaged into membrane vesicles $[15,16]$.

The occurrence of membrane- or cell-surface-associated DLDH has been observed in diverged organisms. The knowledge is well summarized by Siegmann et al. [17], who reported the identification of DLDH as a surface protein exhibiting titanium binding activity in Rhodococcus ruber. In Neiserria [18], streptococci [19], and Mycoplasma [20], DLDH has been identified as a cell-surface factor associated with their pathogenicity. In E. coli, an NADH-dehydrogenase NDH-2 exhibiting marked amino acid sequence similarity with DLDH is also produced as a membrane-associated enzyme [21]. In all these cases, the protein does not contain any secretion signal. Our N-terminal deletion experiment (Fig. 3) indicated that the $\mathrm{N}$-terminal 29 aa region is not crucial to the extracytoplasmic localization. These observations imply the involvement of a signal-independent secretion system. Consistent with this view, a 
secretome study combined with genome-based signal peptide predictions on Bacillus subtilis revealed that about half of the extracellular proteins were not predicted to be transported across the cell membrane [22].

The physiological roles of bacterial extracytoplasmic DLDHs remain to be elucidated. Recently, one of those enzymes of Thermobifida fusca, a cellulose-degrading Actinobacteria, has been shown to effectively prevent repolymerizaion of lignin-degradation products [23]. Hence, this enzyme likely has a role to facilitate the formation of low molecular weight aromatic compounds in soil. We assume that SCO2180 may play a similar role as predicted for the Thermobifida enzyme. The involvement of Streptomyces in lignin metabolism has been inferred by several studies including our discovery of a small laccase EpoA of S. griseus [4]. An alternative idea is that the extracytoplasmic DLDHs are involved in the electron transfer to quinonic substances as a process in the energy metabolism. Humus serves as an electron transmitter due to the content of quinolic structure [24]. In the last few decades it has been revealed that some anaerobic bacteria like Shewanella oneidensis and Geobacter metallireducens have systems to transfer electrons to insoluble minerals directly or via humic substances $[25,26]$. Considering the low oxygen concentration in soil, it seems plausible that actinomycetes have a similar system to produce energy under oxygen-limiting conditions. Although our data are not conclusive, the available evidence suggests the importance and generality of the role of extracytoplasmic DLDH in the saprophytic life of Streptomyces.

\section{Acknowledgements}


We thank Professor Yoshihito Katayama for helpful discussion. This study was supported by the High-tech Research Center Project of MEXT, the Grants-in-aid for Scientific Research (Grant no. 24580128) of JSPS, and the grant from the Institute for Fermentation, Osaka.

\section{References}

[1] P. Dyson, Streptomyces, Caister Academic Press, Norfolk, 2011.

[2] D.A. Hopwood, Streptomyces in Nature and Medicine, Oxford University Press, New York, 2007.

[3] Y. Hayakawa, H. Nonomura, Humic acid-vitamin agar, a new medium for the selective isolation of soil actinomycetes. , J. Ferment. Technol., 65 (1987) 501-509. [4] K. Endo, Y. Hayashi, T. Hibi, K. Hosono, T. Beppu, K. Ueda, Enzymological characterization of EpoA, a laccase-like phenol oxidase produced by Streptomyces griseus, J Biochem, 133 (2003) 671-677.

[5] K. Endo, K. Hosono, T. Beppu, K. Ueda, A novel extracytoplasmic phenol oxidase of Streptomyces: its possible involvement in the onset of morphogenesis, Microbiology, 148 (2002) 1767-1776.

[6] L. Lu, G. Zeng, C. Fan, J. Zhang, A. Chen, M. Chen, M. Jiang, Y. Yuan, H. Wu, M. Lai, Y. He, Diversity of two-domain laccase-like multicopper oxidase genes in Streptomyces spp.: identification of genes potentially involved in extracellular activities and lignocellulose degradation during composting of agricultural waste, Appl Environ Microbiol, 80 (2014) 3305-3314.

[7] S. Majumdar, T. Lukk, J.O. Solbiati, S. Bauer, S.K. Nair, J.E. Cronan, J.A. Gerlt, 
Roles of small laccases from Streptomyces in lignin degradation, Biochemistry, 53 (2014) 4047-4058.

[8] A. de Kok, A.F. Hengeveld, A. Martin, A.H. Westphal, The pyruvate dehydrogenase multi-enzyme complex from Gram-negative bacteria, Biochim Biophys Acta, 1385 (1998) 353-366.

[9] V. Massey, Q.H. Gibson, C. Veeger, Intermediates in the catalytic action of lipoyl dehydrogenase (diaphorase), Biochem J, 77 (1960) 341-351.

[10] T. Kieser, M.J. Bibb, M.J. Buttner, K.F. Chater, D.A. Hopwood, Practical Streptomyces genetics, The John Innes Foundation, Norwich, United Kingdom, 2000. [11] H. Schagger, G. von Jagow, Blue native electrophoresis for isolation of membrane protein complexes in enzymatically active form, Anal Biochem, 199 (1991) 223-231.

[12] B. Gust, G.L. Challis, K. Fowler, T. Kieser, K.F. Chater, PCR-targeted Streptomyces gene replacement identifies a protein domain needed for biosynthesis of the sesquiterpene soil odor geosmin, Proc Natl Acad Sci U S A, 100 (2003) 1541-1546. [13] T. Nishiyama, Y. Hashimoto, H. Kusakabe, T. Kumano, M. Kobayashi, Natural low-molecular mass organic compounds with oxidase activity as organocatalysts, Proc Natl Acad Sci U S A, 111 (2014) 17152-17157.

[14] M. Raberg, J. Bechmann, U. Brandt, J. Schluter, B. Uischner, B. Voigt, M. Hecker, A. Steinbuchel, Versatile metabolic adaptations of Ralstonia eutropha $\mathrm{H} 16$ to a loss of PdhL, the E3 component of the pyruvate dehydrogenase complex, Appl Environ Microbiol, 77 (2011) 2254-2263.

[15] H. Schrempf, I. Koebsch, S. Walter, H. Engelhardt, H. Meschke, Extracellular Streptomyces vesicles: amphorae for survival and defence, Microb Biotechnol, 4 (2011) 286-299. 
[16] H. Schrempf, P. Merling, Extracellular Streptomyces lividans vesicles: composition, biogenesis and antimicrobial activity, Microb Biotechnol, 8 (2015) 644-658.

[17] A. Siegmann, A. Komarska, Y. Betzalel, I. Brudo, S. Jindou, G. Mor, G. Fleminger, The titanium binding protein of Rhodococcus ruber GIN1 (NCIMB 40340) is a cell-surface homolog of the cytosolic enzyme dihydrolipoamide dehydrogenase, J Mol Recognit, 22 (2009) 138-145.

[18] I. Li de la Sierra, L. Pernot, T. Prange, P. Saludjian, M. Schiltz, R. Fourme, G. Padron, Molecular structure of the lipoamide dehydrogenase domain of a surface antigen from Neisseria meningitidis, J Mol Biol, 269 (1997) 129-141.

[19] D. Daniely, M. Portnoi, M. Shagan, A. Porgador, N. Givon-Lavi, E. Ling, R. Dagan, Y. Mizrachi Nebenzahl, Pneumococcal 6-phosphogluconate-dehydrogenase, a putative adhesin, induces protective immune response in mice, Clin Exp Immunol, 144 (2006) 254-263.

[20] S.F. Dallo, T.R. Kannan, M.W. Blaylock, J.B. Baseman, Elongation factor Tu and E1 beta subunit of pyruvate dehydrogenase complex act as fibronectin binding proteins in Mycoplasma pneumoniae, Mol Microbiol, 46 (2002) 1041-1051.

[21] K. Bjorklof, V. Zickermann, M. Finel, Purification of the $45 \mathrm{kDa}$, membrane bound $\mathrm{NADH}$ dehydrogenase of Escherichia coli (NDH-2) and analysis of its interaction with ubiquinone analogues, FEBS Lett, 467 (2000) 105-110.

[22] H. Tjalsma, H. Antelmann, J.D. Jongbloed, P.G. Braun, E. Darmon, R. Dorenbos, J.Y. Dubois, H. Westers, G. Zanen, W.J. Quax, O.P. Kuipers, S. Bron, M. Hecker, J.M. van Dijl, Proteomics of protein secretion by Bacillus subtilis: separating the "secrets" of the secretome, Microbiol Mol Biol Rev, 68 (2004) 207-233.

[23] R. Rahmanpour, L.D. King, T.D. Bugg, Identification of an extracellular bacterial 
flavoenzyme that can prevent re-polymerisation of lignin fragments, Biochem Biophys Res Commun, 482 (2017) 57-61.

[24] C.M. Martinez, L.H. Alvarez, L.B. Celis, F.J. Cervantes, Humus-reducing microorganisms and their valuable contribution in environmental processes, Appl Microbiol Biotechnol, 97 (2013) 10293-10308.

[25] Y.A. Gorby, S. Yanina, J.S. McLean, K.M. Rosso, D. Moyles, A. Dohnalkova, T.J. Beveridge, I.S. Chang, B.H. Kim, K.S. Kim, D.E. Culley, S.B. Reed, M.F. Romine, D.A. Saffarini, E.A. Hill, L. Shi, D.A. Elias, D.W. Kennedy, G. Pinchuk, K. Watanabe, S. Ishii, B. Logan, K.H. Nealson, J.K. Fredrickson, Electrically conductive bacterial nanowires produced by Shewanella oneidensis strain MR-1 and other microorganisms, Proc Natl Acad Sci U S A, 103 (2006) 11358-11363.

[26] D.R. Lovley, J.D. Coates, E.L. Blunt-Harris, E.J.P. Phillips, J.C. Woodward, Humic substances as electron acceptors for microbial respiration, Nature, 382 (1996) 445-448.

\section{Figure Legends}

Fig. 1. Temporal occurrence of NBT-reducing activity in cells and culture media revealed by blue-native PAGE. S. coelicolor A3(2) was grown in $100 \mathrm{~mL}$ of Bennett's/maltose liquid medium. At indicated times post-inoculation, $1 \mathrm{~mL}$ of culture was sampled and subjected to the analysis. Cells from the sample cultures were lysed by sonication in $1 \mathrm{~mL}$ of buffer. Cleared cell-free extracts and culture media were 10-times concentrated using Amicon devices (3,000 NMWL), $10 \mu \mathrm{L}$ of which was loaded on the gel. 
Fig. 2. Purification and identification of extracytoplasmic diaphorase. The following samples were subjected to Coomassie-stained SDS-PAGE (A) and blue-native PAGE with NBT as the staining agent (B): 1, cleared culture medium; 2, 35-70\% saturated ammonium sulfate-precipitate fraction; 3, HiTrap Q column chromatography fraction ; 4, HiTrap Butyl chromatography fraction; 5, Superdex 200 chromatography fraction; 6, Resource $Q$ chromatography fraction. $\mathrm{M}$, molecular weight markers.

Fig. 3. The influence of the N-terminal region of SCO2180 on the expression as an extracellular protein. (A) The N-terminal sequences of the tested SCO2180 derivatives. (B) Detection of the SCO2180 derivatives in the culture media of the expression strains. Samples were analyzed by Coomassie-stained SDS-PAGE. M, molecular weight markers. w/o, without a plasmid.

Fig. 4. Detection of NBT-reducing enzymes intra- and extracellularly produced by Streptomyces soil isolates. The test strains were grown at $28^{\circ} \mathrm{C}$ for 2 days in YMP-glucose media (2 $\mathrm{g} \mathrm{L}^{-1}$ yeast extract, $2 \mathrm{~g} \mathrm{~L}^{-1}$ meat extract, $4 \mathrm{~g} \mathrm{~L}^{-1}$ Bacto Peptone, 5 $\mathrm{g} \mathrm{L}^{-1} \mathrm{NaCl}, 2 \mathrm{~g} \mathrm{~L}^{-1} \mathrm{MgSO}_{4} \cdot 7 \mathrm{H}_{2} \mathrm{O}$, and $10 \mathrm{~g} \mathrm{~L}^{-1}$ of glucose [pH 7.2]). Cell-free extracts and spent culture media were prepared from the cultures and analyzed by blue-native PAGE. Sc, S. coelicolor A3(2). 
Table 1 Coding sequences flanking to SCO2180

\begin{tabular}{ccl}
\hline CDS ID & direction & \multicolumn{1}{c}{ annotation } \\
\hline SCO2178 & - & endo alpha-1,4 polygalactosaminidase \\
SCO2179 & + & leucyl aminopeptidase \\
SCO2180 & + & dihydrolipoamide dehydrogenase (DLDH) \\
SCO2181 & + & 2-oxoacid dehydrogenase, E2 component \\
SCO2182 & + & GntR family transcriptional regulator \\
SCO2183 & + & 2-oxoacid dehydrogenase, E1 component \\
SCO2184 & + & transcriptional regulator \\
SCO2185 & + & hypothetical protein \\
SCO2186 & + & hypothetical protein \\
SCO2187 & - & hypothetical protein \\
\hline
\end{tabular}

Table 2 Substrate specificity of SCO2180 diaphorase

\begin{tabular}{lc}
\hline \multicolumn{1}{c}{ Substrates } & Specific activity $\left(\mu \mathrm{mol} \mathrm{min}^{-1} \mathrm{mg}^{-1}\right)$ \\
\hline DCIP & 1.94 \\
NBT & 0.85 \\
D,L-Lipoamide & 2.31 \\
D,L-Lipoic acid & 0.57 \\
p-benzoquinone & 3.67 \\
2-methyl-1,4-benzoquinone & 2.62 \\
a-naphtoquinone & 1.04 \\
2-methyl-1,4-naphtoquinone & 0.64 \\
2,3,5,6-tetramethyl-1,4-benzoquinone & 0.31 \\
Actinorhodin & 0.12 \\
\hline
\end{tabular}




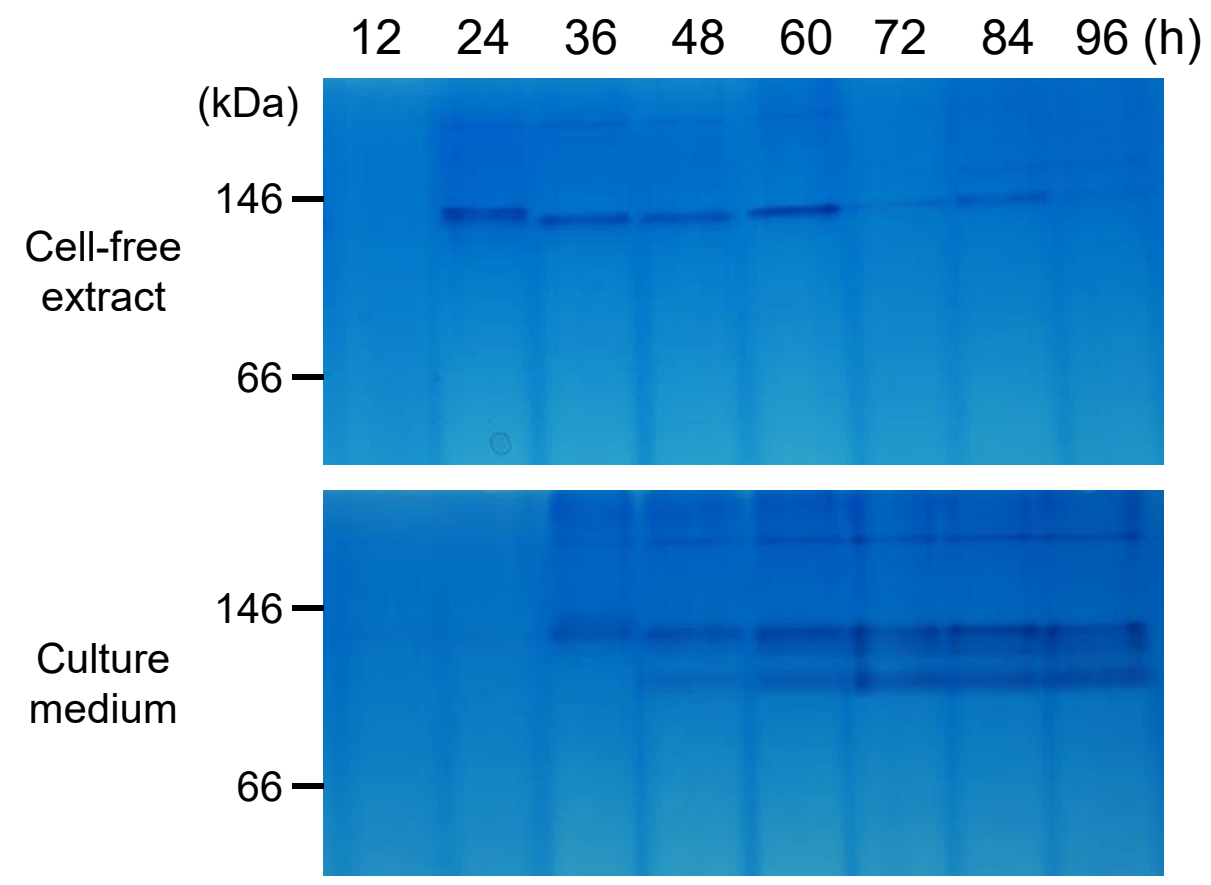

Oinuma_Figure 1 
A

B

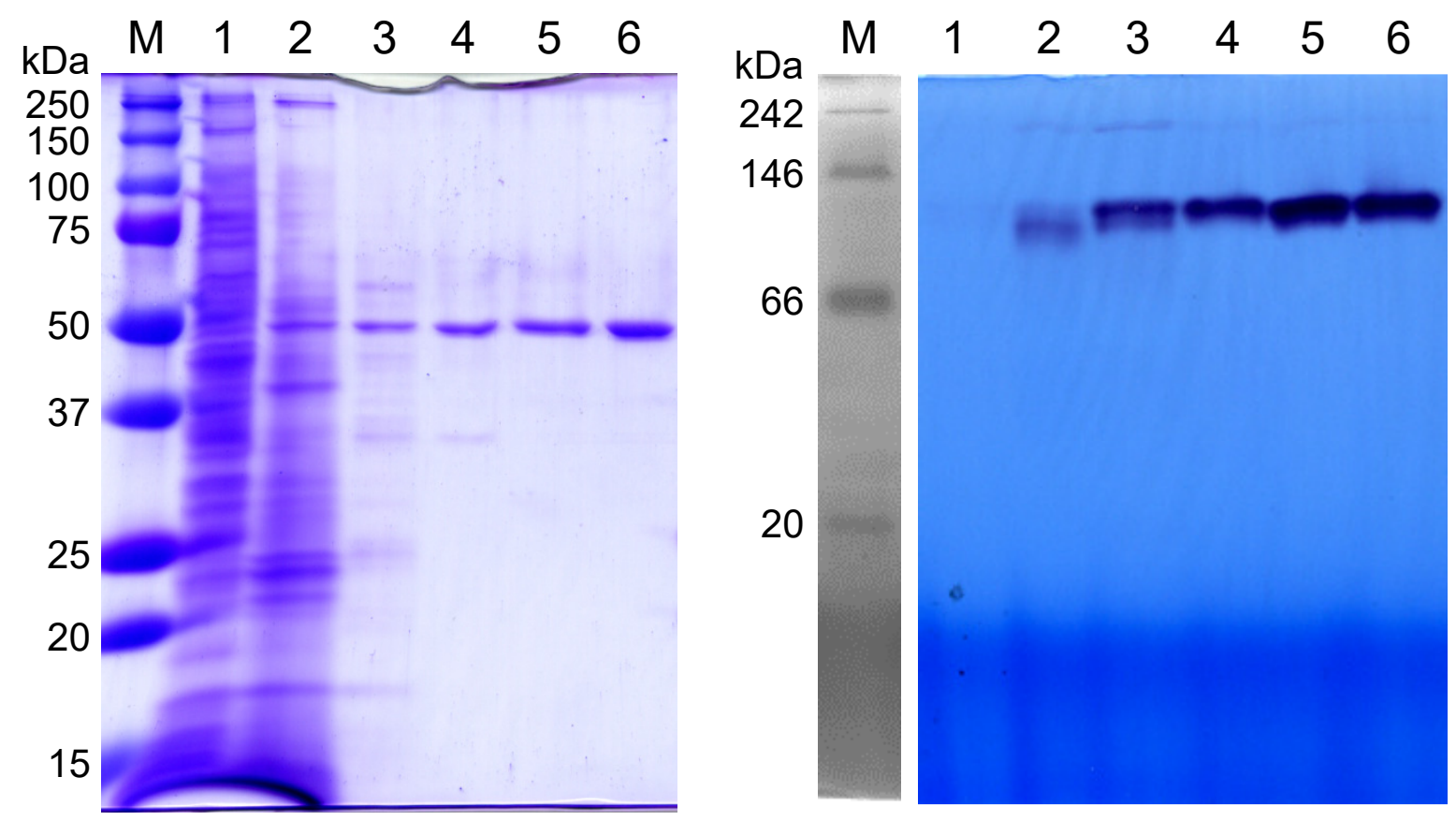

Oinuma_Figure 2 

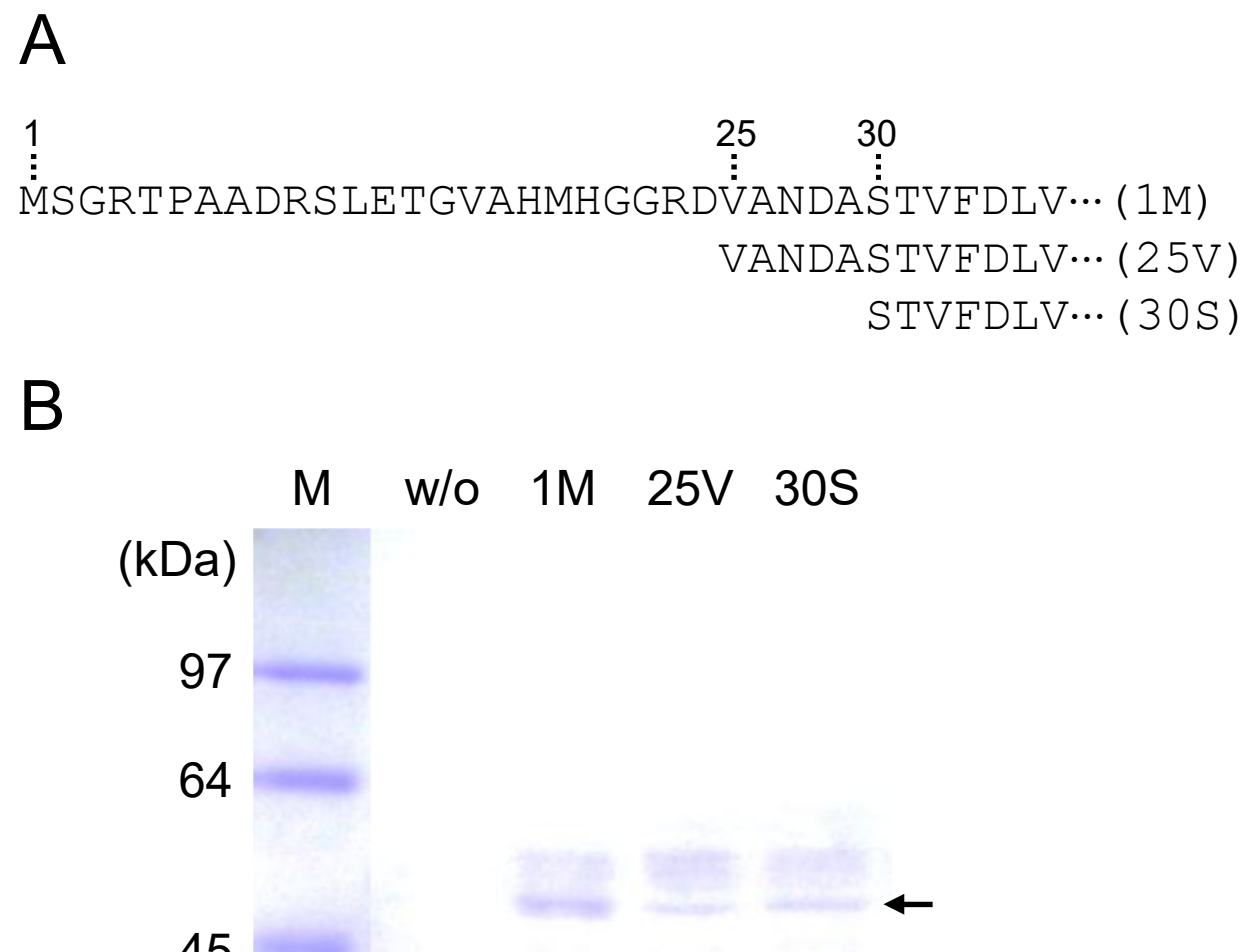

45

30

Oinuma_Figure 3 


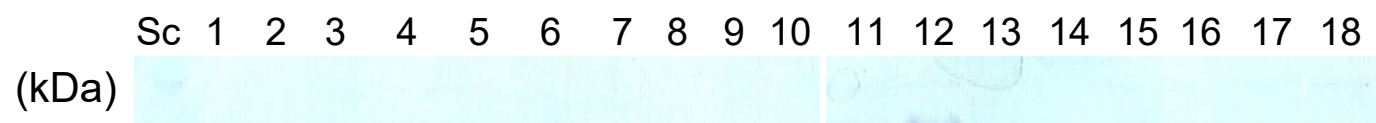

